\title{
Study of Visceral Leishmaniasis (Kala-azar) in Children of Nepal
}

\author{
Joshi DD ${ }^{1}$ \\ ${ }^{1}$ Dr. Durga Datt Joshi, MPVM, FISCD, WHO Expert Panel Member on Zoonoses, Executive Chairman, National \\ Zoonoses and Food Hygiene Research Centre (NZFHRC) GPO Box: 1885 Chagal, Kathmandu, Nepal. Jeevan Smriti \\ Marg House no. 468 Ward no. 13, KMC Phone: +977-1-4270667, +977-1-4272694
}

Address for Correspondence: Dr. Durga Datt Joshi, E-mail: ddjoshi@healthnet.org.np

\begin{abstract}
Introduction: Visceral leishmaniasis (VL) or Kala-azar is a potentially fatal vector-borne (sand fly phlebotomies spp) zoonotic disease caused by a protozoan parasite, Leishmania donovani. In Nepal, the disease is restricted to the Eastern Terai region which lies adjacent to the Bihar state of India. Although leishmaniasis is regarded as a significant health problem in Nepal by the Ministry of Health, there is no active case detection programme in the country. Objective: Objectives of this study were to determine the up-to-date morbidity and mortality trend for VL in children of Nepal. Method: The epidemiological surveillance team from the NZFHRC visited to eight zonal hospitals in Terai region during the month from September to December of each year 2003 to 2007 . The morbidity and mortality data up to the year 2007 were collected every year. The team has also collected 66 blood serum samples of which 18 samples from children were collected for the diagnosis. Results: A total 25890 cases with 599 deaths were reported during the year 1980-2006. The case fatality rate (CFR) varied from $0.23 \%$ to $13.2 \%$. Districtwise analysis showed that, during 2003, highest incidence was in Mahottari district $(184 / 100,000)$, followed by Sarlahi $(100 / 100,000)$ and Sunsari $(96 / 100,000)$. The highest CFR was in Dhanusha $(2.9 \%)$ followed by Bara $(2.4 \%)$ and Saptari $(2.0 \%)$. Majority $(70.9 \%)$ of persons affected by VL were aged 15 years and above, followed by $10-14$ years $(13.9 \%)$, 5-9 years $(11.9 \%)$ and $1-4$ years $(3.3 \%)$. VL cases recorded from different district of Nepal for the year 2004, 2005, 2006 and 2007 are recorded. CFR for the year 2004, 2005, 2006 and 2007 were 3.2\%, 3.7\%, 16.67\% and 11.42\% respectively. Conclusions: There should be regular surveillance research work to be carried out in endemic area. Mass public health education, to make the people aware about preventive aspects of the disease is important. The possibility of the existence of animal reservoirs as zoonotic disease should also be considered. This disease is very much serious in children below 15 years of age both in male and female, therefore it is essential to have paediatrician post at least in all VL six endemic districts.
\end{abstract}

Key words: Epidemiology, Leishmaniasis, Kala-azar, Sandfly

\section{Introduction}

Jepal, together with India, Bangladesh, Sudan and 1 Brazil constitutes the five countries of the world where more that $90 \%$ of VL occurs ${ }^{1}$. VL is endemic in 14 districts of central and eastern regions of Nepal. Nearly six million people residing in these districts are at risk of acquiring this disease. VL in Nepal mostly occurs in the eastern and central Terai regions, bordering with the Bihar State of India, although scattered outbreaks have also been reported in the mid-western and western Terai.

During mid 1970's, when the insecticide-spraying program was stopped; it resulted in higher incidence of VL in the late 1970's. The infection is believed to be introduced from the Indian state of Bihar where an epidemic of Kala-azar took place in $1977^{2,3}$. 
In Nepal, VL is primarily a disease of the poorest of the poor ${ }^{3,4}$. These people usually live in the mud houses having cracked walls and damp floors, which constitute excellent condition for attraction and hiding of sandflies. Moreover, majority of these people sleep outside of their houses during the summer, without bed nets, which is most favourable situation for the sandfly to bite and transmit the infection. Although VL cases are still being reported at lower rate in Nepal since 1998 but this might have also been due to out-migration to the Middle-East counties for employment and carry back infection into Nepal., ${ }^{5,6}$ Regarding cases of Post Kalaazar Dermal Leishmaniasis (PKDL), as it is sequel to kala-azar treatment; abundant cases are found here in Nepal ${ }^{7}$.

The parasite species causing VL in Nepal is Leishmania donovani ${ }^{8}$. In addition, L. tropica, and $L$. major might be occurring in Nepal as they are common in other parts of South-Asia. Regarding the vector, VL has been reported to be transmitted in Nepal by the endophoiles; $P$. argentipes, $P$. papatasi, $P$. sergenti, and Sergentomyia $b_{a b u^{9-10}}$.

In Nepal, VL primarily manifests as fever, anaemia, hepato and spllenomegay, resulting in death if it is untreated. The diagnosis of VL in Nepal is largely based on clinical signs and symptoms, usually combined with positive formal-gel test $\mathrm{t}^{11}$. At present, the most widely used immunological tests to detect VL in Nepal are the nitrocellulose dipstick test that detects antibody to the recombinant amastigote antigen K39 (rK39), direct agglutination test, and latex agglutination test ${ }^{10,11}$.

This study was thus undertaken to determine the up-to-date morbidity and mortality data for visceral leishmaniasis particularly in children of $\mathrm{Nepal}^{12}$.

\section{Materials and Methods}

The survey team from the NZFHRC visited during the month of September to December of each year 2003, 2004, 2005, 2006 and 2007 respectively in eight zonal hospitals in the Terai region. The morbidity and mortality data from 1980 up to the year 2007 were collected from the above mentioned Zonal and District Hospitals of Nepal. During the year 2007 September to December month NZFHRC team members and researcher collected sixty six (66) blood serum samples of which eighteen (18) samples from children and rest forty eight (48) samples from adult male and female patients and eighteen (18) bone marrow samples of which six (6) samples were from children were also collected for the Aldehyde test to confirm the diagnosis.

\section{Results}

\section{Incidence and CFR}

In Nepal Visceral Leishmaniasis (VL) cases were first recorded in 1980 with the incidence rate of 1.5 per 100,000 populations and case fatality rate of $5.9 \%$. Since then VL cases are showing rising trend. However, the case fatality rate (CFR) has been fluctuating. The incidence of VL was highest in 2003 and highest CFR in 1982 (Fig: 1).

Retrospective data analysis showed that during the year 2003, the highest incidence (per 100,000) was in Mahottari district (184) followed by Sarlahi (100), Sunsari (96), Saptari (53), Siraha (45), Dhanusha (31), Parsa (27), Bara (26), Udayapur (25), Morang (20), Jhapa (7), and lowest was in Rautahat district (6). The highest CFR was in Dhanusha (2.9\%) followed by Bara $(2.4 \%)$, Saptari $(2.0 \%)$, Siraha (1.8\%), Sunsari (1.2\%), Mahottari (1.1), Morang (1.1\%) and Sarlahi (0.31\%) (See table 1).

\section{Seasonal distribution}

The seasonal data pattern was interpretted and tabulated. Highest numbers of cases were reported during the rainy season (June to August) and lowest during the winter (September - December) and started to have increased during (Jan. - May) (Fig. 2).

\section{Age-sex distribution}

It has been found that children are more affected than adult. During the year 2003, out of the 1345 Kalaazar cases none $(0 \%)$ were found in infants. In one to four years age group it was seen in 3.3\% and $11.9 \%$ in the age group of five to nine years age. It was found in $13.9 \%$ in the ten to forteen years age group and $65.1 \%$ in $15-59$ years and $5.8 \%$ in $\geq 60$ years. However, CFR did not follow any trend specific to age/sex. The CFR in male children was $13 \%$ and $11 \%$ during 1996 and 1997 and in female children it was $8 \%$ and $13 \%$ respectively.

VL cases recorded in different districts of Nepal during the year 2004, 2005, 2006 and 2007 are presented in Table No; 2, 3, 4 and 5 respectively. CFR 26.8\% for the year 2004 like wise CFR 2.5\%, CFR $17.6 \%$ and CFR $6.1 \%$ for the year 2005, 2006 and 2007 respectively. VL cases for the year 2004, 2005, 2006 and 2007 are also presented in Figure 3,4,5 and 6 respectively.

VL cased recorded in different district of Nepal from August to December 2006 are shown in Table 4. and Fig 5. Most affected districts were Mahottari, Dhanusha, Saptari and Sunsari respectively. 
Table 1: District wise Kala-Azar Incidence and CFR 2001, 2002 \& 2003.

\begin{tabular}{|c|c|c|c|c|c|c|c|}
\hline \multirow{2}{*}{ District } & \multirow{2}{*}{ Population at risk } & \multicolumn{2}{|c|}{2001} & \multicolumn{2}{|c|}{2002} & \multicolumn{2}{|c|}{2003} \\
\hline & & Incidence & CFR & Incidence & CFR & Incidence & CFR \\
\hline Mahottari & 387360 & NA & $\mathrm{NA}$ & 81.1 & 1.27 & 184.3 & 1.12 \\
\hline Sarlahi & 324829 & 83.4 & 0.00 & 58.8 & 0.00 & 100.4 & 0.31 \\
\hline Sunsari & 250813 & 51.8 & 0.00 & 71.0 & 0.00 & 96.9 & 1.23 \\
\hline Saptari & 563796 & 61.2 & 0.86 & 68.1 & 1.30 & 53.4 & 1.99 \\
\hline Siraha & 497816 & 59.1 & 1.36 & 55.8 & 0.00 & 45.2 & 1.78 \\
\hline Dhanusha & 441689 & 39.2 & 0.00 & 33.5 & 0.68 & 31.5 & 2.88 \\
\hline Parsa & 25400 & 114.2 & 3.44 & 94.5 & 0.00 & 27.6 & 0 \\
\hline Bara & 305283 & 62.6 & 0.00 & 63.2 & 0.52 & 26.9 & 2.44 \\
\hline Udayapur & 147800 & 43.3 & 6.25 & 25.7 & 0.00 & 25.7 & 0 \\
\hline Morang & 465801 & 25.5 & 2.52 & 34.8 & 0.62 & 20.4 & 1.05 \\
\hline Jhapa & 296471 & 16.9 & 2.00 & 11.8 & 0.00 & 7.4 & 0 \\
\hline Rautahat & 452307 & 15.5 & 1.42 & 15.0 & 0.00 & 6.6 & 0 \\
\hline Total & 4159365 & 41.7 & 0.98 & 48.8 & 0.69 & 53.4 & 1.30 \\
\hline
\end{tabular}

NA=Data not available

Table 2: VL Cases recorded in Different Districts of Nepal during the year 2004.

\begin{tabular}{|l|c|c|c|c|}
\hline \multicolumn{1}{|c|}{ District } & $\begin{array}{c}\text { Total admitted case both } \\
\text { adult and children }\end{array}$ & $\begin{array}{c}\mathbf{1 - 1 5} \text { yrs age } \\
\text { admitted cases }\end{array}$ & $\begin{array}{c}\text { Total Death } \\
\text { Children Cases }\end{array}$ & $\begin{array}{c}\text { Case Fatality } \\
\text { (children)Rate/100 }\end{array}$ \\
\hline Bara & 12 & 2 & 1 & 50.0 \\
\hline Saptari & 248 & 40 & 5 & 12.5 \\
\hline Sunsari & 143 & 30 & 10 & 33.3 \\
\hline Sarlahi & 15 & 5 & 1 & 20.0 \\
\hline Dhanusha & 137 & 7 & 2 & 28.5 \\
\hline Total & $\mathbf{5 5 5}$ & $\mathbf{7 1}$ & $\mathbf{1 9}$ & $\mathbf{2 6 . 8}$ \\
\hline
\end{tabular}

Table 3: VL Cases recorded in Different Districts of Nepal during the Year 2005.

\begin{tabular}{|l|c|c|c|c|}
\hline District & $\begin{array}{c}\text { Total admitted case } \\
\text { both adult and children }\end{array}$ & $\begin{array}{c}\mathbf{1 - 1 5} \text { yrs age } \\
\text { admitted cases }\end{array}$ & $\begin{array}{c}\text { Total Death } \\
\text { Children Cases }\end{array}$ & $\begin{array}{c}\text { Case Fatality } \\
\text { Rate/100 }\end{array}$ \\
\hline Sarlahi & 265 & 135 & 5 & 3.7 \\
\hline Sunsari & 227 & 105 & 4 & 3.8 \\
\hline Udayapur & 152 & 62 & 1 & 1.6 \\
\hline Saptari & 301 & 195 & 3 & 1.5 \\
\hline Dhanusha & 235 & 135 & 2 & 1.5 \\
\hline Rautahat & 50 & 10 & 1 & 1.5 \\
\hline Total & $\mathbf{1 2 3 0}$ & $\mathbf{6 4 3}$ & $\mathbf{1 6}$ & $\mathbf{2 . 5}$ \\
\hline
\end{tabular}

Table 4: VL Cased recorded in Different District of Nepal from Aug to Dec2006.

\begin{tabular}{|l|c|c|c|c|}
\hline District & $\begin{array}{c}\text { Total admitted case } \\
\text { both adult and children }\end{array}$ & $\begin{array}{c}\mathbf{1 - 1 5} \text { yrs age } \\
\text { admitted cases }\end{array}$ & $\begin{array}{c}\text { Total Death } \\
\text { Children Cases }\end{array}$ & $\begin{array}{c}\text { Case Fatality } \\
\text { Rate/100 }\end{array}$ \\
\hline Mahottari & 42 & 11 & 1 & 9.1 \\
\hline Rautahat & 6 & 4 & 1 & 25.0 \\
\hline Sarlahi & 2 & 2 & 0 & 0.0 \\
\hline Morang & 6 & 1 & 1 & 100.0 \\
\hline Saptari & 12 & 4 & 0 & 0.0 \\
\hline Dhanusha & 20 & 6 & 2 & 33.3 \\
\hline Sunsari & 11 & 4 & 1 & 25.0 \\
\hline Kapilbastu & 9 & 2 & 0 & 0.0 \\
\hline Total & $\mathbf{1 0 8}$ & $\mathbf{3 4}$ & $\mathbf{6}$ & $\mathbf{1 7 . 6}$ \\
\hline
\end{tabular}


Table 5: VL Cases Recorded in Different District of Nepal during the year 2007.

\begin{tabular}{|l|c|c|c|c|}
\hline District & $\begin{array}{c}\text { Total admitted case } \\
\text { both adult and children }\end{array}$ & $\begin{array}{c}\mathbf{1 - 1 5} \text { yrs age } \\
\text { admitted cases }\end{array}$ & $\begin{array}{c}\text { Total Death } \\
\text { Children Cases }\end{array}$ & $\begin{array}{c}\text { Case Fatality } \\
\text { Rate/100 }\end{array}$ \\
\hline Saptari & 85 & 20 & 1 & 5.0 \\
\hline Siraha & 18 & 5 & 0 & 0.0 \\
\hline Jhapa & 36 & 2 & 0 & 0.0 \\
\hline Sarlahi & 131 & 105 & 5 & 4.8 \\
\hline Makwanpur & 14 & 4 & 1 & 25.0 \\
\hline Rautahat & 31 & 12 & 2 & 16.7 \\
\hline Total & $\mathbf{3 1 5}$ & $\mathbf{1 4 8}$ & $\mathbf{9}$ & $\mathbf{6 . 1}$ \\
\hline
\end{tabular}

\section{Aldehyde and bone marrow test result}

Table 6: Aldehyde and Bone Marrow Test Result for Kala-Azar in Siraha District Hospital.

\begin{tabular}{|l|c|c|c|c|c|c|c|c|c|}
\hline & \multicolumn{2}{|c|}{$\begin{array}{c}\text { Aldehyde Test } \\
\text { Only }\end{array}$} & \multicolumn{2}{c|}{$\begin{array}{c}\text { Only Bone } \\
\text { Marrow Test }\end{array}$} & \multicolumn{3}{c|}{$\begin{array}{c}\text { Both aldehyde (A) \& bone marrow } \\
\text { (BM) test }\end{array}$} & \multicolumn{2}{c|}{ Total Samples } \\
\hline Age & $\mathrm{n}$ & $\%+\mathrm{ve}$ & $\mathrm{n}$ & $\%+\mathrm{ve}$ & $\mathrm{n}$ & $\%$ BM +ve \& A - ve & $\%$ Both +ve & $\mathrm{n}$ & $\%$ ve \\
\hline $0-4$ & 2 & 50.0 & 0 & 0 & 0 & 0 & 0 & 2 & 50.0 \\
\hline $5-9$ & 2 & 50.0 & 1 & 0 & 0 & 0 & 0 & 3 & 33.3 \\
\hline $10-14$ & 8 & 100.0 & 5 & 100.0 & 2 & 100.0 & 0 & 15 & 100.0 \\
\hline $15-19$ & 6 & 83.3 & 0 & 0 & 0 & 0 & 0 & 6 & 83.3 \\
\hline Total & 18 & 27.8 & 6 & 33.33 & 2 & 11.11 & 00 & 26 & 84.6 \\
\hline
\end{tabular}

Of the total eighteen $(\mathrm{n}=18)$ suspected patients with Kala-azar were tested by aldehyde and bone-marrow methods. Among them, 33.33\% (6/18) were positive for aldehyde test only and $83.3 \%(5 / 6)$ for bone-marrow only. Of the eighteen $(n=18)$ tested by both methods,
$11.1 \%(2 / 18)$ were bone marrow positive but aldehyde negative and $0.0 \%(0 / 18)$ by both tests. The age related pattern was nearly uniform except among children aged below nine years, where only $11.1 \%$ could be confirmed by any of these tests.

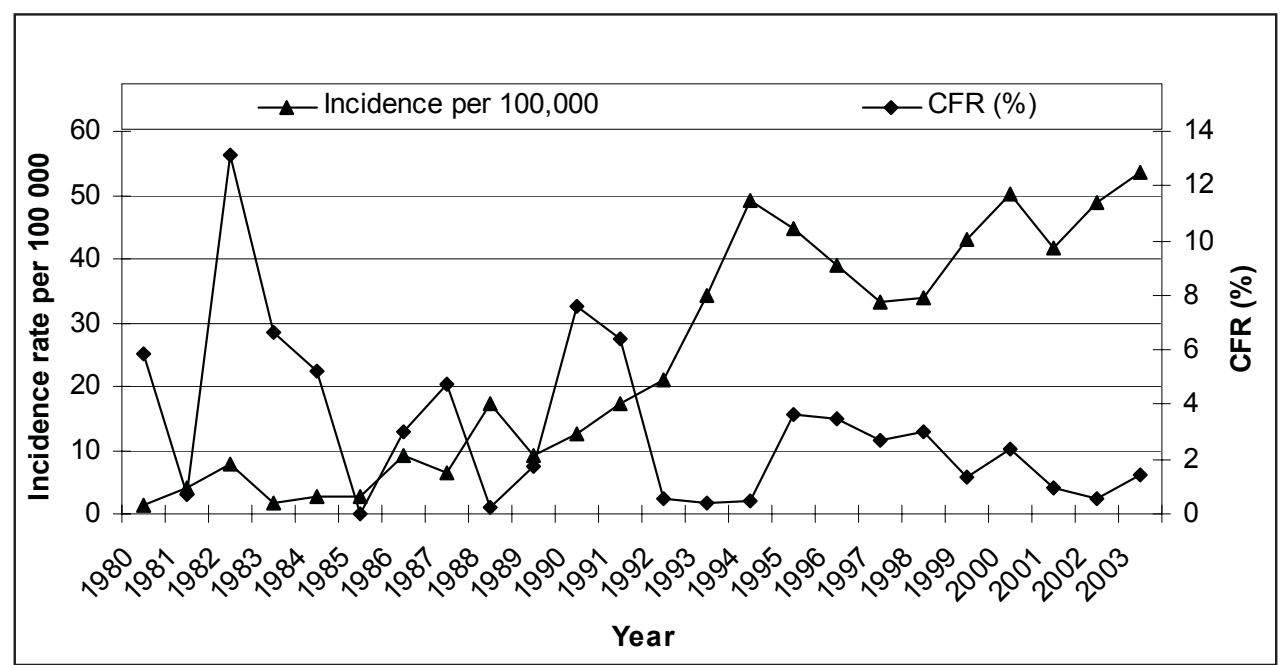

Fig. 1: Incidence and Case-Fatality Rate of Visceral Leishmaniasis in Nepal, 1980-2003 


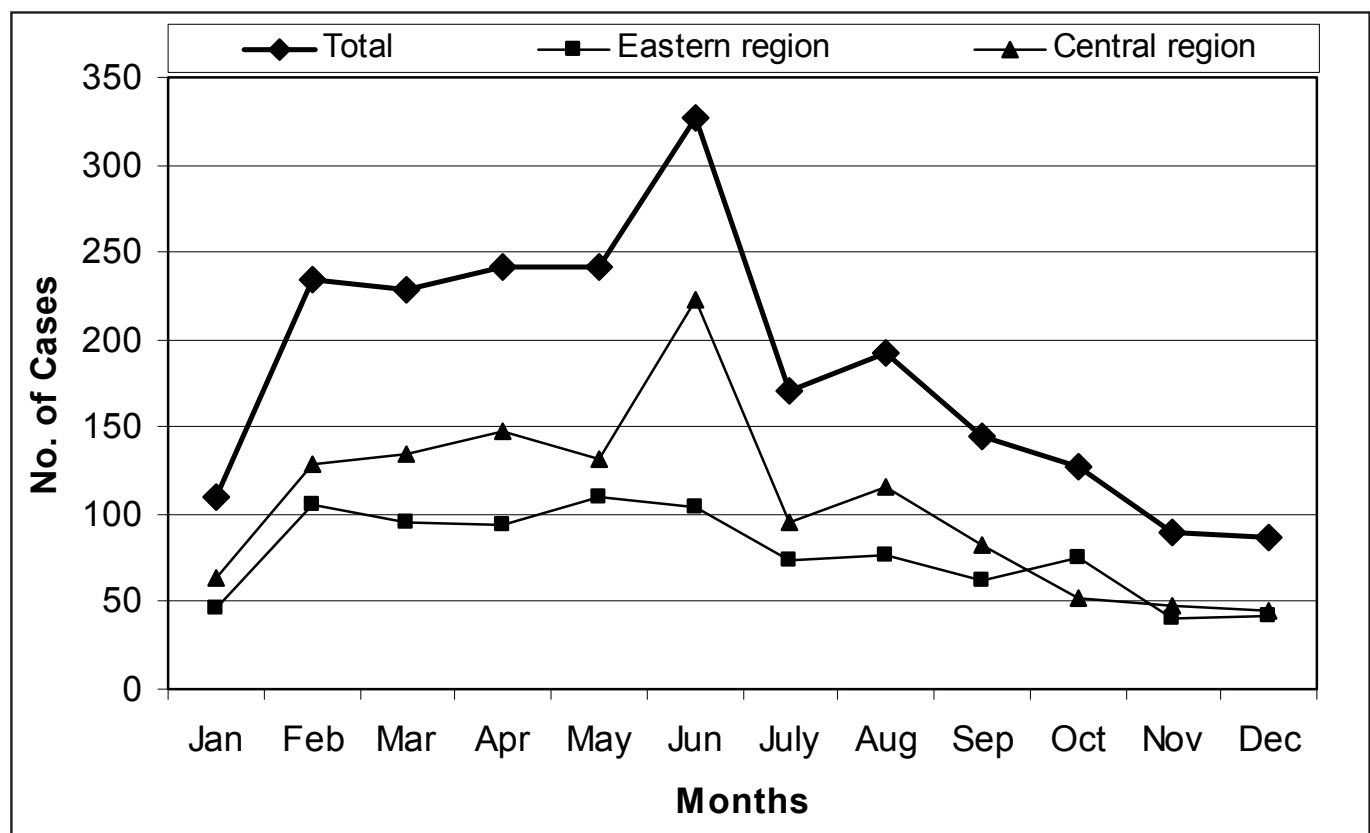

Fig 2: Showing the Seasonal Trend of VL throughout the year in the Eastern and Central Regions of the Country.

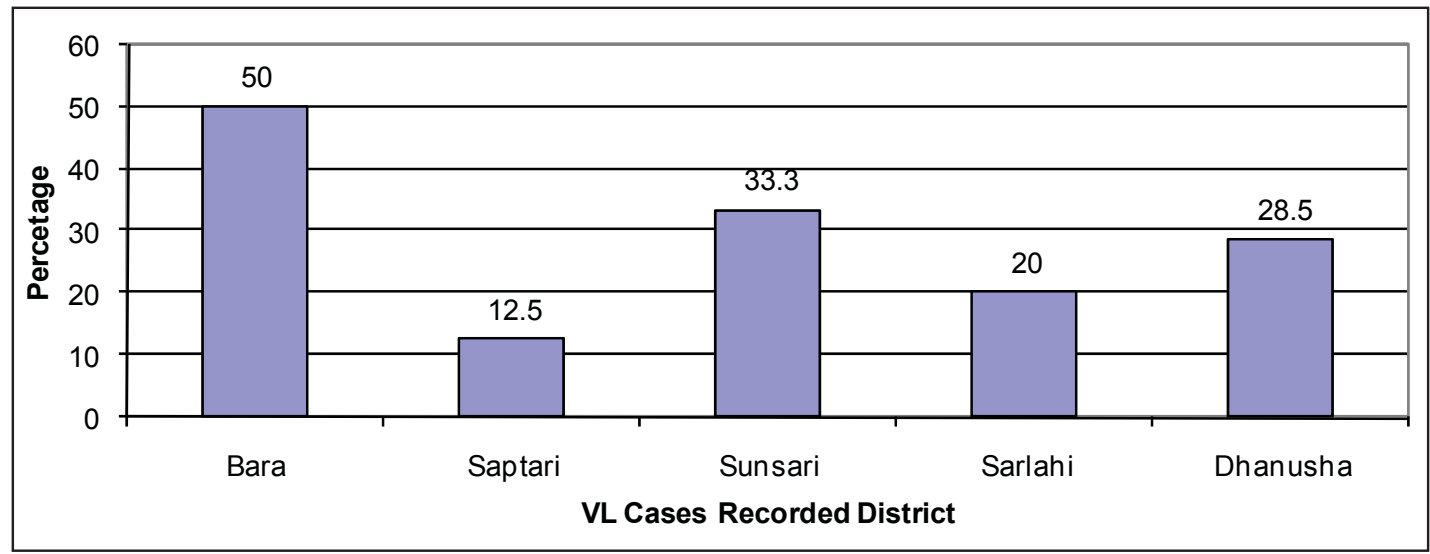

Fig 3: VL Cases recorded in Different Districts of Nepal in 2004.

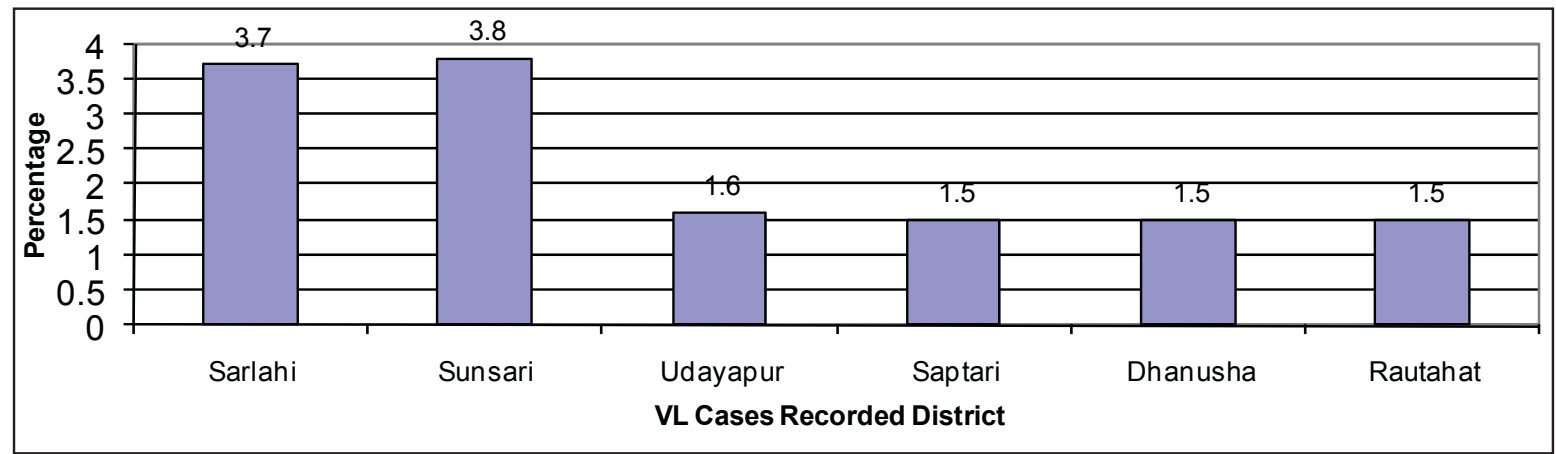

Fig 4: VL Cases recorded in Different Districts of Nepal during the Year 2005. 


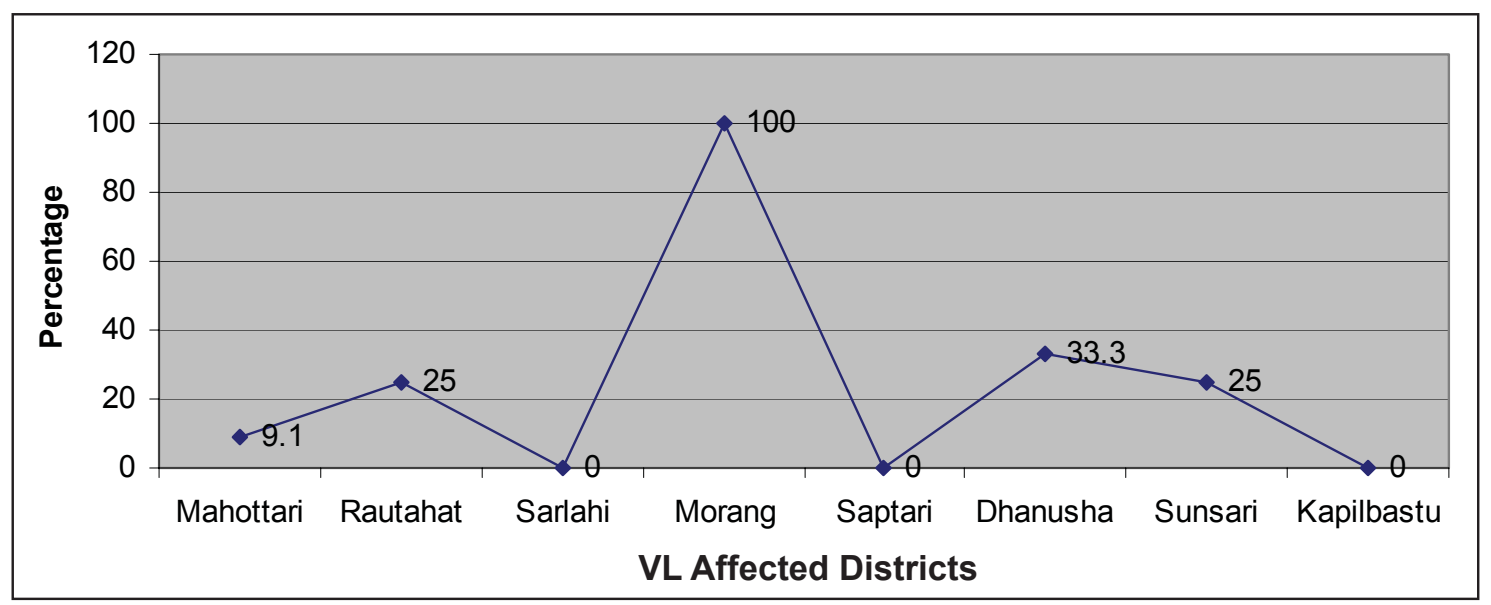

Fig 5: VL Cases Recorded in Different District of Nepal from Aug to Dec 2006.

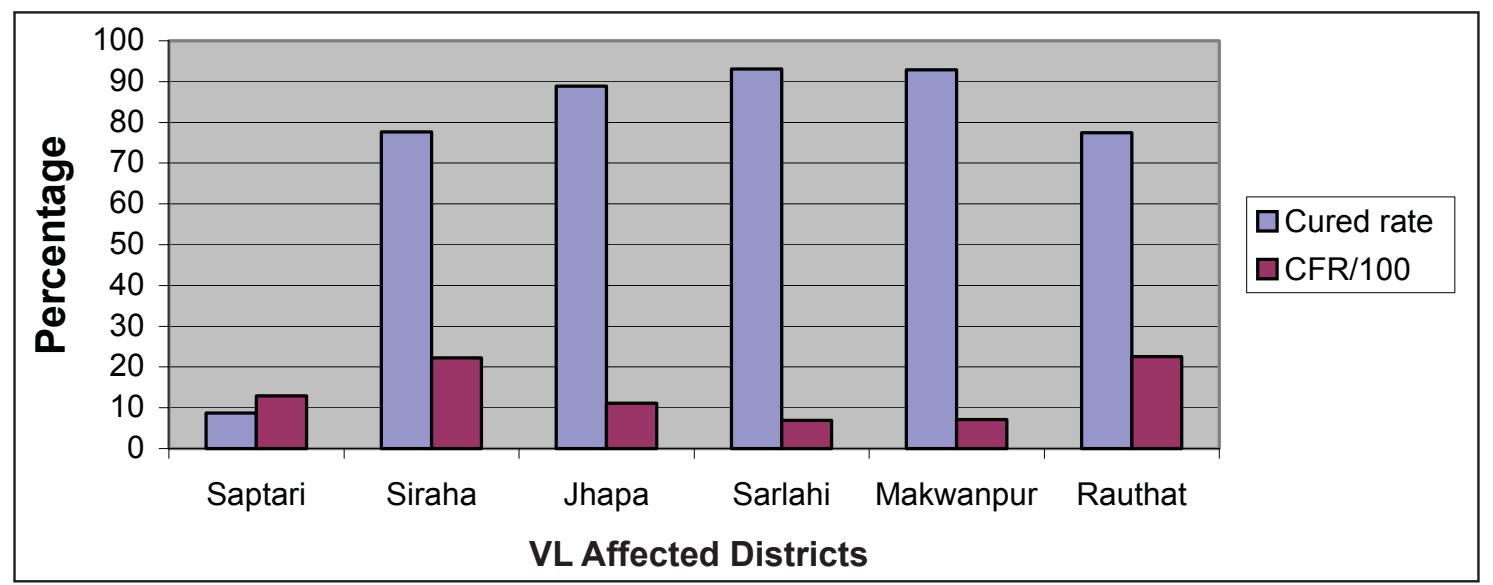

Fig 6: VL Cases Recorded in Different District of Nepal 2007.

\section{Discussion}

In comparison with the baseline incidence data in the epidemiological and socio-economical surveillance report on Leishmaniasis in Nepal, for 1996 and 1997, the number of kala-azar cases has approximately doubled during 1998-1999. Bista (1998) ${ }^{5}$ also observed that the number of reported cases had increased dramatically over the past five years and that the current situation could be considered epidemic in the affected areas. Out of total sixty six $(n=66)$ serum samples collected forty $(n=40)$ were tested by aldehyde test only out of which $32(80 \%)$ found positive. Similarly, seven out of eight $(87.5 \%)$ were found positive for bone marrow test and four out of eighteen $(22.2 \%)$ tested positive for both aldehyde and bone marrow methods. In Nepal, VL primarily manifests as fever, anaemia, spleno- and hepatomegaly, resulting in death if it is untreated. The diagnosis of VL in Nepal is largely based on clinical signs and symptoms, usually combined with positive formal-gel test. Reference laboratories and regional hospitals routinely use some serological tests. The most important factor responsible for this resurgence seems to be discontinuation of the DDT spraying campaigns in many areas, failure of detection of diseases among people, inaccessibility or unaffordability of poor to the treatment and lack of awareness among these people about the preventive aspects of the disease. Therefore, extensive spraying in all endemic areas is the need of the time. In the meantime, measures like popularising use of bednets (Government may consider providing it on subsidy for the population in affected areas), extensive surveillance, prompt diagnosis and treatment along with effective health education should be undertaken to avoid future epidemic. They should also be taught to protect while sleeping, take measures to contain sandfly growth and habitat in cracks \& dampness in their houses, maintain hygiene to keep the surrounding free of sandfly.

\section{Conclusion}

Visceral leishmaniasis (kala-azar) cases are suggesting an increasing trend in Nepal. There should be regular surveillance research work to be carried out in both epidemic and non-epidemic districts of the country. Mass public health education, to make the 
people aware about preventive aspects of the disease is important. The possibility of the existence of animal reservoirs as zoonotic disease should also be considered and checked out for better control measures. This disease is very much serious in children below 15 years of age both in male and female, therefore it is essential to have paediatricians posted at least in all six VL endemic districts of eastern terai region. There should be a special refresher training regarding the clinical therapy given to the paediatricians. This will help in decreasing the mortality of the children due to kala-azar.

\section{Acknowledgement}

I am grateful to all the Directors of the Regional, Zonal and District Hospitals of the country for their kind cooperation during survey study and paper writing. I am thankful to all the staff of NZFHRC particularly Ms. Meena Dahal for the computer data analysis.

Funding: This study was funded by DDJ Research Foundation, Chagal, Kathmandu, Nepal.

Conflict of Interest: There could be some conflict of interest to some of the public health authorities by using DDT or any other insecticide to control sand fly but it is very much essential to have in Nepal.

\section{References}

1. WHO. World Health Organisation. TDR Strategies direction: Leishmaniasis. 2002. Available on http:// www.who.int/tdr/disease/leish/files/direction/pdf

2. Gratz NG. Emerging and resurging vector-borne diseases. Ann Rev Entomol 1999; 44:51-57.

3. Chelala C. The poor man's disease. In: Himal Southasian. 2004.

4. Bista MB. National Overview of Kala-azar in Nepal. In: Kala-azar in Nepal: Principles, Practice and Public Health Perspectives. Epidemiology and Disease Control Division, Dept. of Health Services. Kathmandu. 1998; 40-45 pp.
5. Parija SC, Jacob M, Karki BMS, Manoj S, Karki P, Koirala S. Cutaneous Leishmaniasis in Nepal. Southeast Asian J Trop Med Pub Health 1998; $1: 29$.

6. Desjeux P. Leishmaniasis: Current Situation and New Perspectives. Compar Immunol Microbiol \& Infect Dis 2004;27:305-18

7. Garg VK, Agrawal S, Rani S, Joshi A, Agrawa A, Das ML and Koirala S. Post-Kala-Azar Dermal Leishmaniasis in Nepal. Inter J Dermatol 2001; 40 .

8. Devkota UN. Descriptive Epidemiology of Visceral Leishmaniasis in Nepal 1993. J Nepal Med Assoc 1993;31: 329-326

9. Shrestha SL and Pant SK. Seasonal Distribution of Phlebotomine Sand Flies-Vector of Visceral Leishmaniasis. J Nepal Med Assoc 1994; 32: 237 46.

10. Bern C, Jha SN, Joshi AB, Thakur GD and Bista MB. Use of the Recombinant K39 Dipstick Test and the Direct Agglutination Test in a Setting Endemic for Visceral Leishmaniasis in Nepal. Am J Trop Med Hyg 2000;63:153-57

11. Rijal S, Chappuis F, Singh R, Bovier PA, Acharya P, Karki BMS, Das ML, Desjeux P, Loutan L and Koirala S. Treatment of Visceral Leishmaniasis in South-Eastern Nepal: Decreasing Efficacy of Sodium Stibogluconate and Need for a Policy to Limit Further Decline. Trans Royal Soc Trop Med Hyg 2003;97:350-4,

12. Joshi DD, Visceral Leishmaniasis (VL) Kalaazar Outbreaks Recorded in Nepal During the Year 2005, 2006, 2007. NZFHRC/DDJ Research Foundation Nepal. 2007;1-90. 